\title{
Widespread distribution in human tissues of an antigenic determinant of granulocytes
}

\author{
ALEXANDER J HOWIE, GEOFFREY BROWN, ${ }^{*}$ AMANDA G FISHER, \\ MAHMOOD KHAN*
}

From the Departments of Pathology and *Immunology, University of Birmingham, Edgbaston, Birmingham B15 2TJ

SUMmARY The monoclonal antibodies AGF4.48 and AGF4.36 have previously been shown to distinguish human granulocyte lineage cells from other peripheral blood and bone marrow cells. The AGF4.48 antigen, which is carbohydrate in nature, together with similar antigens described by numerous investigators have been considered specific differentiation antigens of myeloid cells. In immunohistological studies of a wide range of normal tissues, the AGF4.48 antibody selectively stained cells in several apparently unrelated tissues. These included proximal tubules and descending thin limbs in the kidney, parietal cells in the stomach, a variety of other epithelial cells, astrocytes in the brain, and cells in the anterior pituitary containing adrenocorticotrophic hormone. The AGF4.36 antibody gave similar results on kidney, stomach and pituitary. These findings emphasise the importance of assessing the binding of monoclonal antibodies, which appear unique in their reactivity with blood cells, to non-haemopoietic tissues before assigning specificity to reagents. The distribution of cells expressing the AGF4.48 and AGF4.36 antigen correlates with the occurrence of the 3-fucosyl- $\mathrm{N}$-acetyllactosamine carbohydrate structure in various secreted glycoproteins.

Numerous monoclonal antibodies have been described which distinguish human granulocytes ${ }^{1-4}$ and monocytes ${ }^{5-7}$ from other peripheral blood cells. Underlying much of this work has been an assumption that the antigenic determinants detected by these monoclonal antibodies are specific for granulocyte and monocyte lineage cells. Although this has been shown to be true when the antibodies have been extensively tested against various haemopoietic cells, there has been no formal investigation of unrelated tissues to confirm or refute this assumption.

Recent biochemical investigations have shown that the antibodies VEP8, VEP9, and 1G10, which identify myeloid antigens, recognise the carbohydrate structure 3-fucosyl- $\mathrm{N}$-acetyllactosamine, sometimes termed X-hapten. ${ }^{89}$ This oligosaccharide has the following structure:

$\beta$-D-Galactose $1 \rightarrow 4$ [ $\alpha$-L-Fucose $1 \rightarrow 3$ ] $N$-acetyl-D-glucosamine Techniques for carbohydrate analysis have shown that this sequence can be detected in a variety of glycoproteins including $\alpha_{1}$-acid glycoprotein, ${ }^{10}$ lactoferrin, ${ }^{11}$ parotid $\alpha$-amylase,,$^{12}$ cervical mucin, ${ }^{13}$ and secretory component. ${ }^{14}$ It is not known, however, whether the $\mathrm{X}$-hapten structure is a distinctive marker of cells producing these glycoproteins or

Accepted for publication 26 January 1984 cryptic and masked by additional sugar residues. This point can be investigated by staining various human tissues using monoclonal antibodies to carbohydrate antigens.

In this study we present a systematic immunohistological study of the reactivity of two monoclonal antibodies, raised against the promyeloid cell line HL60, with various non-haemopoietic tissues. Among haemopoietic tissues these antibodies identify antigens restricted to myeloid cells.' AGF4.48 identified an antigen expressed throughout the promyeloid to neutrophil stages of maturation and absent from monocytes. The specificity of this antibody is similar if not identical to that described for the VEP8 antibody. ${ }^{8} 15$ In contrast, the AGF4.36 antigen is expressed at the promyeloid to metamyeloid stages of myelopoiesis and absent from most blood neutrophils and monocytes. We relate the reactivity of these antibodies with diverse cells in several organs to the occurrence of the X-hapten structure in various glycoproteins.

\section{Material and methods}

\section{ANTIBODIES}

The murine monoclonal antibodies AGF4.36 (IgM) and AGF4.48 (IgM) were originally raised against the human promyeloid cell line HL60. The production and specificity of these antibodies have been 
described in detail previously. ${ }^{1}$ For immunohistology, supernatants from hybridoma cultures were used undiluted. AGF4.48 supernatant was absorbed with HL60 cells and used as an absorption control.

Various polyclonal antisera to pituitary hormones were also used to stain serial sections cut from blocks of pituitary glands. These were rabbit antisera to luteinising hormone, follicle stimulating hormone, prolactin, growth hormone, and thyroid stimulating hormone (all from the Department of Clinical Endocrinology, Birmingham and Midland Hospital for Women, Birmingham), and rabbit antiadrenocorticotrophic hormone (May and Baker). For these antisera the second stage was swine antirabbit immunoglobulins linked to horseradish peroxidase (Dakopatts).

\section{PREPARATION OF TISSUE SAMPLES}

Fresh material from a nephrectomy specimen was frozen in liquid nitrogen and cryostat sections (5$10 \mu \mathrm{m}$ in thickness) were cut. The sections were fixed in acetone for $10 \mathrm{~min}$ at room temperature and air dried. Samples from the same kidney were also fixed in various ways: formol-saline, $5 \%$ acetic acid in neutral buffered formalin, Zenker's fluid, and Bouin's fluid. These samples were paraffin embedded. Preliminary experiments showed that parts of the kidney reacted with the antibody AGF4.48 using a two stage immunoperoxidase method and that the best results were obtained with paraffin embedded material that had been fixed in formolsaline. All other material was therefore fixed in formol-saline and paraffin embedded. Fresh samples of normal tissues (shown in the Table) were obtained from surgical specimens with the exception of samples of adrenal, brain, myocardium, parathyroid, skeletal muscle, and spinal cord, which were taken at necropsy.

IMMUNOPEROXIDASE STAINING

A two stage immunoperoxidase method was used. ${ }^{16}$ Endogenous peroxidase was first blocked in paraffin embedded sections by one of two ways. (1) Sections were dewaxed in xylene and transferred to alcohol (99\% industrial methylated spirit). A method based on that of Streefkerk ${ }^{17}$ was then used. Sections were covered with $0.5 \%$ hydrogen peroxide in methanol, and rocked for $10 \mathrm{~min}$ at room temperature. After rinsing in alcohol, the sections were washed in tap water. (2) Sections were taken through xylene and alcohol to water. They were covered successively with $2.5 \%$ hydrogen peroxide in distilled water for $5 \mathrm{~min}$, aqueous $0.1 \mathrm{M}$ periodic acid for $5 \mathrm{~min}$, and $0.02 \%$ potassium borohydride in distilled water for $2 \mathrm{~min}$, with water washes between each step. ${ }^{16}$ Sections were finally washed in tap water. Supernatant containing antibody $(50-100 \mu \mathrm{l})$ was added to sections either directly if they were frozen sections or after rinsing sections in phosphate buffered saline,

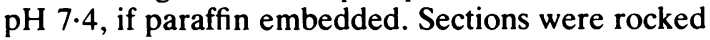
at room temperature in a covered chamber for $30 \mathrm{~min}$. After a rinse with phosphate buffered saline the sections were immersed in a bath of phosphate buffered saline containing the detergent BRIJ 96 $(0.001 \%)$ (Sigma) and stirred for $15 \mathrm{~min}$. The second stage antibody in the immunoperoxidase method was sheep antiserum to mouse immunoglobulins $\mathbf{G}, \mathbf{A}$, and $\mathbf{M}$, linked to horseradish peroxidase (Serotec). This was diluted $1 / 50$ in phosphate buffered saline containing $1 \%$ ovalbumin. After incubation for $30 \mathrm{~min}$ and washing as for the first stage, sections were covered with $1 \mathrm{mg} / \mathrm{ml}$ solution of diaminobenzidine tetrahydrochloride and hydrogen peroxide $(0.01 \%)$ in phosphate buffered saline. After 3-5 min at room temperature sections were rinsed in water, stained with Mayer's haematoxylin, dehydrated, and mounted in Ralmount (RA Lamb).

\section{Results}

When tested against formol fixed and paraffin embedded bone marrow samples the AGF4.48 antibody stained all cells of the myeloid series

Immunoperoxidase labelling of non-haemopoietic tissue with the monoclonal antibody AGF4.48

\begin{tabular}{|c|c|c|}
\hline System & Positive staining & Negative staining \\
\hline Alimentary & $\begin{array}{l}\text { Oesophageal, gastric, colonic, and gall bladder } \\
\text { mucosa; ducts and acini of salivary glands; acini } \\
\text { of pancreas; hepatocytes }\end{array}$ & $\begin{array}{l}\text { Other parts of wall of oesophagus, stomach, colon, } \\
\text { and gall bladder; ileum, bile ducts }\end{array}$ \\
\hline Genitourinary & $\begin{array}{l}\text { Parts of nephron; pelvic, ureteric, and bladder } \\
\text { mucosa; prostatic glands; endocervical and } \\
\text { endometrial glands; ectocervical and } \\
\text { vaginal mucosa }\end{array}$ & $\begin{array}{l}\text { Rest of kidney, ureter, bladder, and prostate; testis, } \\
\text { endometrial stroma, myometrium, uterine tube, } \\
\text { ovary, trophoblast }\end{array}$ \\
\hline Endocrine & $\begin{array}{l}\text { A sub-population of cells in anterior } \\
\text { pituitary }\end{array}$ & $\begin{array}{l}\text { Rest of pituitary; thyroid, parathyroid, adrenal, } \\
\text { islets of Langerhans }\end{array}$ \\
\hline Nervous & Astrocytes, ependyma & $\begin{array}{l}\text { Other glial cells, neurones, peripheral nerves, } \\
\text { autonomic ganglia }\end{array}$ \\
\hline Others & Breast: lactating lobules, resting ducts & $\begin{array}{l}\text { Adipose tissue, fibrous tissue, skin, blood vessels, } \\
\text { heart, lung, nasal mucosa, skeletal muscle, } \\
\text { synovium, bone, cartilage }\end{array}$ \\
\hline
\end{tabular}


except myeloblasts, as described previously.' The technique used to block endogenous peroxidase affected the reactivity of AGF4.48 with bone marrow cells. Strong staining was observed when hydrogen peroxide in methanol was used to block endogenous peroxidase. Sections pretreated with periodic acid were unstained by the AGF4.48 antibody. All results are therefore reported on sections treated with hydrogen peroxide in methanol. Neutrophil polymorphs were often present in sections of organs other than bone marrow and stained strongly, even in postmortem material. The staining pattern of neutrophils showed peripheral accentuation and sometimes a granular intracytoplasmic appearance.

The staining patterns seen in non-haemopoietic tissues are listed in the Table and some are illustrated in Figs. 1-10. The AGF4.48 antibody stained a variety of epithelial cells, including cells in some exocrine glands. Superficial squames and desmosomes were stained in the stratified squamous epithelium of tonsil, oesophagus (Fig. 1), ectocervix, vagina, and thymus, but not of skin. In gastric mucosa the glands stained up to the mucous neck cells (Fig. 2). Staining was seen in the circumnuclear invagination of parietal cells (Fig. 3), on the luminal border of most cells up to the neck, and in an occasional small basal cell. A little paranuclear staining was seen in a few basal cells in colonic mucosa. Many epithelial cells were positive in gall bladder epithelium including the mucus in goblet cells. A few acini were stained in salivary glands and pancreas, and a few duct cells in salivary glands. There was light diffuse staining in the cytoplasm of hepatocytes.

The AGF4.48 antibody stained only proximal tubular cells and the descending thin limb of the loop of Henle in the nephron (Figs. 4 and 5). The pars recta of outer cortical nephrons and all parts of the proximal tubule of deep cortical nephrons reacted most strongly, especially the luminal brush border. Patchy staining was seen in transitional epithelium, especially in superficial cells. Endocervical glands and secretions in their lumina (Fig. 6), basal endometrial cells, and a very few prostatic epithelial cells were positive. In non-lactating breast the luminal border of a few duct cells was stained and in lactating breast many lobular cells and their secreted material were positive (Fig. 7).

There was a fine network of AGF4.48 positive staining in the central nervous system, especially in white matter and in the granular layer of the cerebellum. This was due to staining of astrocyte cell bodies and processes. with accentuation around blood vessels (Fig. 8). In the spinal cord a few ependymal cells were positive. Cytoplasmic granules of some cells in the anterior pituitary gland reacted with the anti- body AGF4.48 (Fig. 9). Use of serial sections showed that these cells contained adrenocorticotrophic hormone and that cells containing luteinising hormone, follicle stimulating hormone, prolactin, growth hormone, and thyroid stimulating hormone did not react with AGF4.48 (Fig. 10).

The monoclonal antibody AGF4.36 was tested for reactivity against sections of bone marrow, kidney, stomach, and pituitary. In bone marrow AGF4.36 detected early myeloid cells except myeloblasts, but in contrast to AGF4.48, this antibody failed to stain most neutrophil polymorphs, as reported previously. ${ }^{\prime}$ On the other organs AGF4.36 gave similar results to AGF4.48.

The absorption of antibody AGF4.48 with HL60 cells removed its reactivity when tested on sections of bone marrow, kidney, stomach, and pituitary, showing that positive staining was not due to binding of any non-immunoglobulin component in the tissue culture supernatant detected by the second antibody reagent.

\section{Discussion}

In this study we have shown that formalin fixed, paraffin embedded tissues gave strong labelling reactions when stained with AGF4.48 antibody, revealed using an indirect immunoperoxidase method. The AGF4.48 antibody, which identifies an antigen selectively expressed by granulocytes among peripheral blood cells,' readily identified myeloid cells in tissue sections. Furthermore, this antibody showed restricted staining patterns in various nonhaemopoietic tissues which had not been previously reported for this or any other monoclonal antibody with a similar specificity.

The antigenic determinant recognised by AGF4.48 is a carbohydrate, as shown by the sensitivity of the AGF4.48 determinant to oxidation by periodic acid. This antibody also shows a similar specificity to the VEP8 antibody, which identifies the oligosaccharide 3-fucosyl- $\mathrm{N}$-acetyllactosamine. ${ }^{8}$ The patterns of staining of cervical epithelium and salivary glands by AGF4.48 are in agreement with reports of the occurrence of the above sugar structure on secreted glycoproteins in cervical mucin ${ }^{13}$ and parotid $\alpha$-amylase. ${ }^{22}$ Reactivity of AGF4.48 antibody with gastric glands is compatible with the finding that the enzyme $\alpha$-3-L-fucosyltransferase required for the addition of fucose to the $\mathrm{C} 3$ position of $\mathrm{N}$-acetyl-glucosamine can be detected in gastric secretions. ${ }^{18}$ In lactating breast the reaction of AGF4.48 can be partly explained by the presence of the milk oligosaccharide lacto- $\mathrm{N}$-fucopentaose III, which contains the $\mathrm{X}$-hapten sugar sequence and also binds the My-l antimyeloid monoclonal antibody. ${ }^{i 4}$ These observations strongly suggest that 


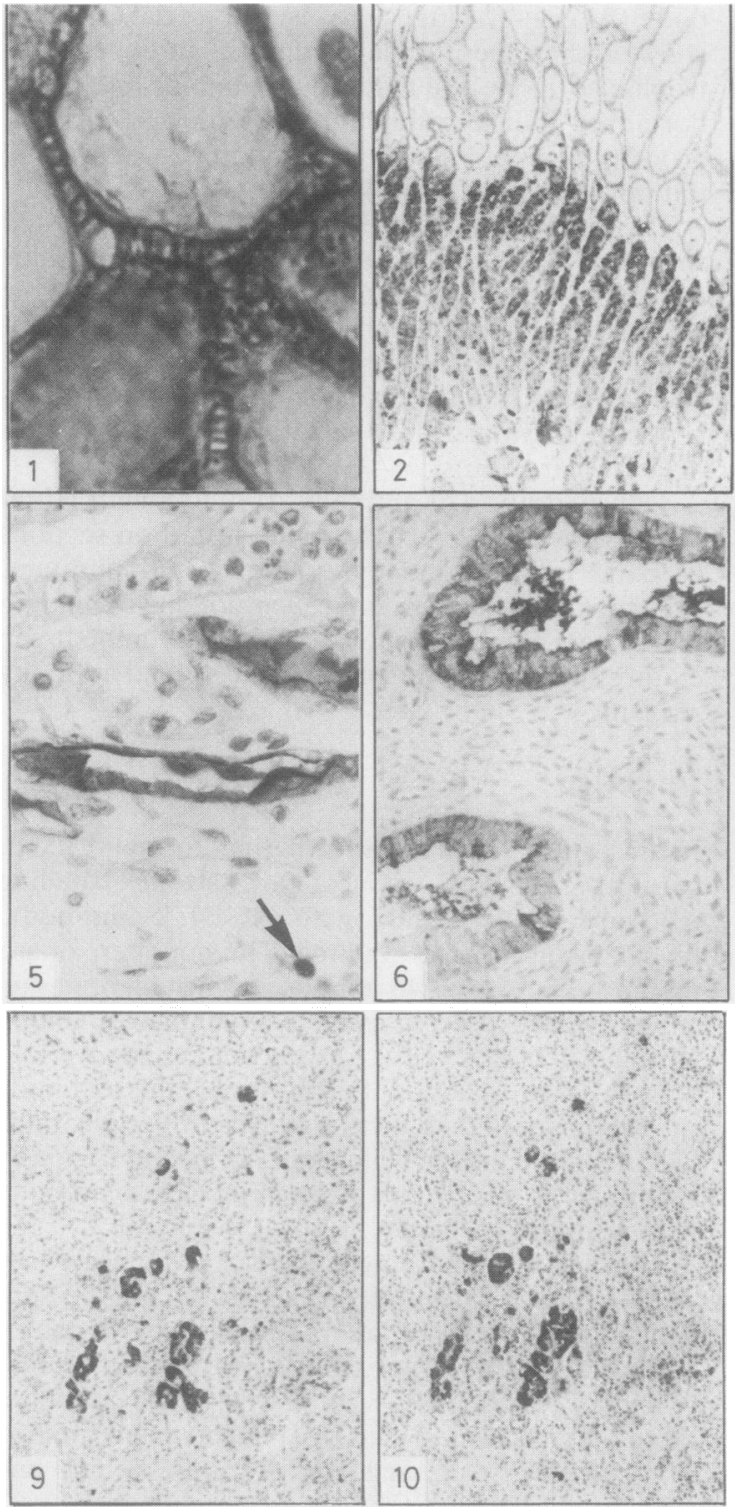

Fig. 1 A high power micrograph of the stratified squamous epithelium of the oesophagus. The antibody AGF4.48 stains desmosomes connecting the squamous cells and their cell membranes. Immunoperoxidase. Original magnification $\times 1600$.

Fig. 2 Full thickness of gastric body type mucosa. Glands are stained by AGF4.48 from their bases up to the mucous neck cells. Immunoperoxidase. Original magnification $\times 60$.

Fig. 3 High power micrograph of a gastric gland in Fig. 2. The strongest staining by AGF4.48 is of the intracellular canaliculus in an acid secreting parietal cell.

Immunoperoxidase. Original magnification $\times 1600$.
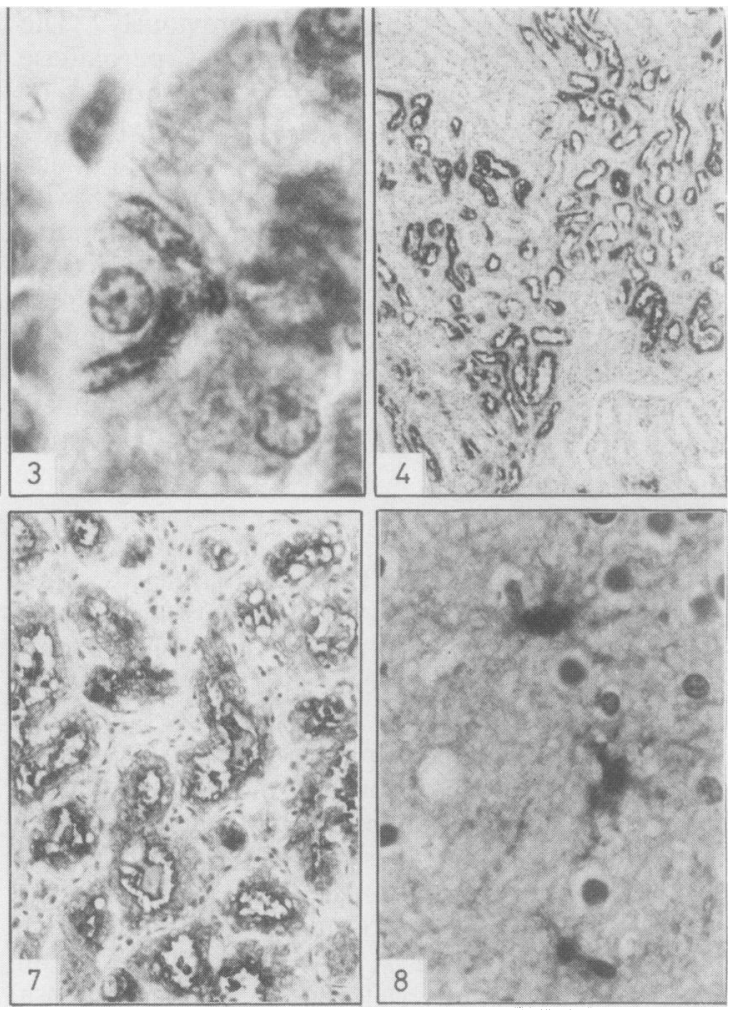

Fig. 4 Inner cortex of the kidney. AGF4.48 stains only a few structures, which are the juxtamedullary parts of proximal tubules. Immunoperoxidase. Original magnification $\times 60$.

Fig. 5 Renal medulla. Epithelium of the thin limbs of the loop of Henle, in the centre of the micrograph, is stained by AGF4.48. The antibody also stains a neutrophil polymorph in a small blood vessel (arrowed). Immunoperoxidase. Original magnification $\times 400$.

Fig. 6 Endocervical glands in the uterus. Epithelial cells and luminal secretions are stained by AGF4.48.

Immunoperoxidase. Original magnification $\times 160$.

Fig. 7 A lobule in lactating breast. The luminal border of epithelial cells and material in the glandular lumens are stained by AGF4.48. Immunoperoxidase. Original magnification $\times 160$.

Fig. 8 White matter of cerebrum. The cell bodies and dendritic processes of several astrocytes are stained by AGF4.48. Immunoperoxidase. Original magnification $\times 640$.

Fig. 9 Anterior part of pituitary gland. Only a few cells are stained by AGF4.48. Immunoperoxidase. Original magnification $\times 60$.

Fig. 10 Anterior part of pituitary gland. The adjacent section to Fig. 9. Anti-adrenocorticotrophic hormone detects the same cells as AGF4.48. Immunoperoxidase. Original magnification $\times 60$. 
the AGF4.48 antibody recognises the 3-fucosyl-Nacetyllactosamine sequence.

Immunohistological analyses showed the overt presence and cellular localisation of the AGF4.48 determinant within various additional tissues. This carbohydrate structure appeared to be membrane associated in duct cells of many glands and renal tubular cells. In stratified squamous epithelium, such as in the oesophagus, the AGF4.48 determinant appeared to be localised on desmosomes. The staining was in cytoplasmic granules in anterior pituitary cells containing adrenocorticotrophic hormone and diffuse in the cytoplasm of the cell bodies and protoplasmic processes of astrocytes.

The importance of the distribution of the carbohydrate determinant recognised by AGF4.48 is at present unclear. Furthermore, it appears that this structure is in some way modified on mature neutrophils. The AGF4.36 antibody partially inhibited the binding of AGF4.48 antibody to HL60 cells and stained intermediate differentiated myeloid cells, pituitary, stomach, and kidney sections but failed to bind to mature neutrophils. ${ }^{\text {' }}$ The relation between the occurrence of particular sugar sequences within carbohydrate chains of cell surface glycoproteins or glycolipids, or both, and their role as specific recognition structures ${ }^{20}$ remains to be elucidated.

Although the monoclonal antibodies reported in this study have now been shown not to be specific for myeloid cells, they may still have several practical applications in immunohistology, especially as we have shown that the antigenic determinant that they recognise is preserved after formalin fixation and paraffin embedding. In disorders of lymphoid and haemopoietic organs these antibodies may be useful as markers of myeloid cells from promyelocytes to mature neutrophil polymorphs. In renal diseases they may be useful as markers of specific parts of the nephron. The antibodies may help in the study of anterior pituitary cells containing adrenocorticotrophic hormone in health and disease. They may also be of use in neuropathology as detectors of astrocytes. Finally, the variable occurrence of the AGF4.48 antigenic determinant in normal epithelial tissues may be reflected in variable expression of the determinant in epithelial neoplasms. These monoclonal antibodies may be found to detect certain types of neoplastic cell or to indicate their ability to produce certain glycoproteins, which may be important in diagnosis and treatment.

We thank the Endowment Fund Medical Research Committee, Central Birmingham Health District $(\mathrm{AJH})$ and the Leukaemia Research Fund (GB) for financial support. AGF is a recipient of an MRC scholarship.

\section{References}

' Fisher AG, Bunce CM, Toksoz D, et al. Studies of human myeloid antigens using monoclonal antibodies and variant lines from the promyeloid cell line HL60. Clin Exp Immunol 1982;50:374-81.

${ }^{2}$ Perussia B, Trinchieri G, Lebman D, et al. Monoclonal antibodies that detect differentiation surface antigens on human myelomonocytic cells. Blood 1982;59:382-92.

${ }^{3}$ Ball ED, Graziano RF, Shen L, et al. Monoclonal antibodies to novel myeloid antigens reveal human neutrophil heterogeneity. Proc Natl Acad Sci USA 1982;79:5374-8.

${ }^{4}$ Civin CI, Mirro J, Banquerigo ML. My-1. A new myeloid-specific antigen identified by a mouse monoclonal antibody. Blood 1981;57:842-5.

s Todd RF, Nadler LM, Schlossman SF. Antigens on human monocytes identified by monoclonal antibodies. J Immunol 1981;126: 1435-42.

- Ugolini V, Nunez G, Smith GR, et al. Initial characterization of monoclonal antibodies against human monocytes. Proc Natl Acad Sci USA 1980;77:6764-8.

7 Todd RF, Schlossman SF. Analysis of antigenic determinants on human monocytes and macrophages. Blood 1982; 59:775-86.

${ }^{8}$ Gooi HC, Thorpe SJ, Hounsell EF, et al. Marker of peripheral blood granulocytes and monocytes of man recognised by two monoclonal antibodies VEP8 and VEP9 involves the trisaccharide 3-fucosyl-N-acetyllactosamine. Eur J Immunol 1983;13:306-12.

9 Andrews RG, Torok-Storb B, Bernstein ID. Myeloid-associated differentiation antigens on stem cells and their progeny identified by monoclonal antibodies. Blood 1983;62:124-32.

${ }^{10}$ Fournet B, Montreuil J, Strecker G, et al. Determination of the primary structures of 16 asialo-carbohydrate units derived from human plasma $\alpha$-acid glycoprotein by $360-\mathrm{MHz}{ }^{\prime} \mathrm{H}$ NMR spectroscopy and permethylation analysis. Biochem 1978;17:5206-14.

" Montreuil J. Primary structure of glycoprotein glycans. Basis for the molecular biology of glycoproteins. Adv Carbohyd Chem Biochem 1980;37:157-223.

12 Yamashita K, Tachibana Y, Nakayama T, et al. Structural studies of the sugar chains of human parotid $\alpha$-amylase. J Biol Chem 1980;255:5635-42.

${ }_{13}$ Yurewicz EC, Matsuura F, Moghissi KS. Structural characterization of neutral oligosaccharides of human midcycle cervical mucin. J Biol Chem 1982;257:2314-22.

${ }^{14}$ Mizoguchi A, Mitzuachi T, Kobata A. Structures of the carbohydrate moieties of secretory component purified from human milk. J Biol Chem 1982;257:9612-21.

${ }^{15}$ Knapp W, Majdic O, Rumpold H, et al. Myeloid differentiation antigens as defined by monoclonal antibodies. In: Knapp W, ed. Leukaemic markers. London: Academic Press, 1981: 207-23.

${ }^{10}$ Heyderman E. Immunoperoxidase technique in histopathology: applications, methods, and controls. J Clin Pathol 1979; 32: 971-8.

${ }^{17}$ Streefkerk JG. Inhibition of erythrocyte pseudoperoxidase activity by treatment with hydrogen peroxide following methanol. $J$ Histochem Cytochem 1972;20:829-31.

${ }^{1 *}$ Chester MA, Watkins WM. $\alpha$-L-fucosyltransferases in human submaxillary gland and stomach tissues associated with the $H$, $\mathrm{Le}^{\mathrm{a}}$ and $\mathrm{Le}^{\mathrm{b}}$ blood-group characters and $\mathrm{ABH}$ secretor status. Biochem Biophys Res Commun 1969;34:835-42.

${ }^{14}$ Huang LC, Civin $\mathrm{CI}$, Magnani JL, et al. My-l, the human myeloid-specific antigen detected by mouse monoclonal antibodies, is a sugar sequence found in lacto- $\mathrm{N}$-fucopentaose III Blood 1983;61: 1020-3.

${ }^{20}$ Gooi HC, Feizi T, Kapadia A, et al. Stage-specific embryonic antigen involves $\alpha 1 \rightarrow 3$ fucosylated type 2 blood group chains. Nature 1981;292: 156-8.

Requests for reprints to: Dr AJ Howie, Department of Pathology, The Medical School, Birmingham B15 2TJ, England. 